\title{
Associating Polymer Networks Based on Cyclodextrin Inclusion Compounds for Heavy Oil Recovery
}

\author{
Xi Li $\mathbb{D}^{1},{ }^{1}$ Zheng Shu, ${ }^{2,3}$ Pingya Luo, ${ }^{2}$ and Zhongbin Ye $\mathbb{D}^{1,2}$ \\ ${ }^{1}$ College of Chemistry and Chemical Engineering, Southwest Petroleum University, Chengdu 610500, China \\ ${ }^{2}$ State Key Laboratory of Oil and Gas Reservoir Geology and Exploitation, Southwest Petroleum University, Chengdu 610500, China \\ ${ }^{3}$ College of Petroleum Engineering, Southwest Petroleum University, Chengdu 610500, China \\ Correspondence should be addressed to Xi Li; lixifantasy@sina.com
}

Received 9 August 2017; Revised 30 November 2017; Accepted 14 January 2018; Published 8 February 2018

Academic Editor: José M. G. Martinho

Copyright (c) $2018 \mathrm{Xi} \mathrm{Li} \mathrm{et} \mathrm{al.} \mathrm{This} \mathrm{is} \mathrm{an} \mathrm{open} \mathrm{access} \mathrm{article} \mathrm{distributed} \mathrm{under} \mathrm{the} \mathrm{Creative} \mathrm{Commons} \mathrm{Attribution} \mathrm{License,} \mathrm{which}$ permits unrestricted use, distribution, and reproduction in any medium, provided the original work is properly cited.

\begin{abstract}
This work evaluates an approach to improve the enhanced heavy oil recovery performance of hydrophobic associating polymer. A polymeric system based on water-soluble hydrophobic associating polymer (WSHAP) and cyclodextrin (CD) polymer was proposed in this work. Addition of CD polymer to WSHAP forms interpolymer bridges by inclusion of CD groups with hydrophobic tails, and thereby the network structure is strengthened. The proposed system offers good viscoelasticity, pronounced shear thinning, and interesting viscosity-temperature relations. Sand pack tests indicated that the proposed system can build high resistance factor during the propagation in porous media, and its moderate adsorption phenomenon was represented by the thickness of the adsorbed layer. The relationship between effective viscosity and oil recovery increment indicated that the proposed system can significantly reduce the residual oil saturation due to the "piston-like" propagation. The overall oil recovery was raised by 5.7 and $24.5 \%$ of the original oil in place compared with WSHAP and partially hydrolyzed polyacrylamide (HPAM), respectively.
\end{abstract}

\section{Introduction}

About $15-30 \%$ of the original oil in place (OOIP) is produced by the natural energy of reservoirs. Additional $10-20 \%$ oil recovery of OOIP can be produced by water injection after primary production [1-3]. More than half of OOIP remains in the reservoir. One of the major problems associated with water injection is unfavorable mobility ratio between the displacing and the displaced phases, which leads to the injection water to finger or channel through reservoirs, resulting in poor sweep efficiency. And this problem is more serious in reservoirs with high viscosity oil. Polymer flooding is the technology wherein high molecular weight, water-soluble polymers are added to the injection water to increase the viscosity and to reduce the mobility ratio [4]. Usually, sweep efficiency can be effectively improved by a low concentration polymer solution. In addition, it has been reported that displacement efficiency can even be raised by the elasticity of polymer solution $[5,6]$. Polymer flooding has been proved to be an efficient method for improving oil recovery.
Traditionally, thermal method was the most effective technique to improve heavy oil recovery. And reservoirs with oil viscosity greater than $200 \mathrm{mPa} \cdot \mathrm{s}$ are not suitable for polymer flooding due to severe viscous fingering $[7,8]$. However, with the increase of energy demand and the consumption of light oil, the emphasis on the development of the vast heavy oil resources is increasing. Thus, as one of the most promising enhanced oil recovery (EOR) technologies, more and more attention has been paid to the polymer flooding field. It is particularly important for thin pay thickness and/or deep reservoirs, which are not suitable for thermal methods.

In general, partially hydrolyzed polyacrylamide (HPAM) is the most commonly used polymer in EOR due to its rapid soluble and efficient thickening ability and some biopolymers such as xanthan gum are also used in EOR [9]. In addition, water-soluble hydrophobic associating polymer (WSHAP) incorporating a small number of hydrophobic groups in the polymer backbone is commercially available [10]. The advantage of this novel polymer is that, in aqueous solution, the hydrophobic groups of WSHAP can associate to minimize 


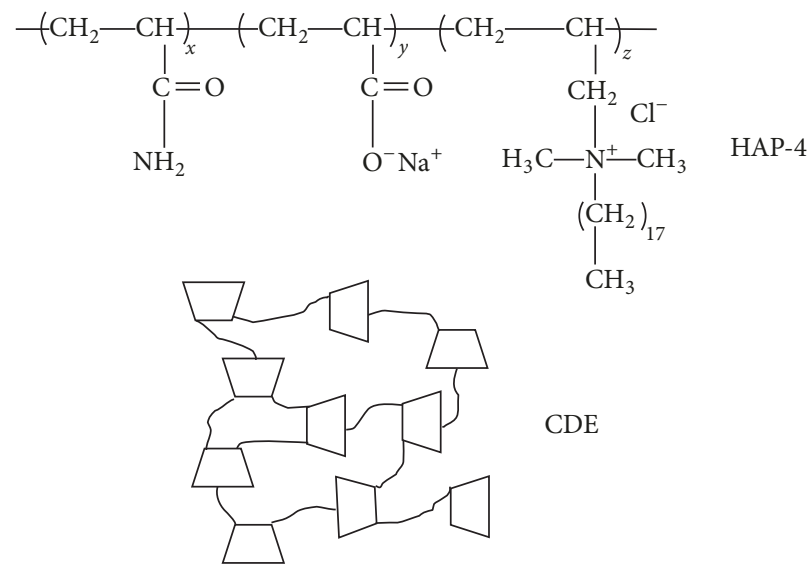

FIGURE 1: Schematic structure of HAP-4 and CDE. CDE displays a hyperbranched architecture.

their exposure to the solvent, thereby greatly increasing the solution viscosity above its critical micelle concentration. Recent pilot tests conducted by the China National Offshore Oil Corporation illustrate the potential of WSHAP flooding [11]. However, due to the high manufacturing cost, these polymers are still limited in large-scale applications [12].

The major concerns for polymer flooding are the effectiveness and cost of the selected polymer system. It is particularly important for heavy oil reserves unsuitable for thermal method, which often require more viscous displacement fluids (or higher polymer concentrations) and larger slug size to avoid unsteady displacement front and to improve volumetric sweep efficiency. EOR applications in heavy oil reservoirs call for more efficient thickening or low cost polymer systems.

Cyclodextrins (CDs) have been widely studied in supramolecular chemistry [13]. Their ability to modulate hydrophobic interactions of WSHAP in aqueous solution is well known. These molecules are cyclic oligosaccharides of glucose units linked together by 1,4- $\alpha$-glucosidic bonds which display a doughnut-shaped structure. The most common CDs are composed of 6,7 , or 8 glucose units named $\alpha-, \beta$, and $\gamma$-CD, respectively. The specific structure provides an external hydrophilic region as well as a hydrophobic inner cavity. In the presence of CD monomers, previous studies on aqueous solutions of WSHAPs have demonstrated that the CD monomers can encapsulate the suspended hydrophobes and deactivate hydrophobic associations $[14,15]$. As a result, the viscosity at low shear and another rheological property of the solution are reduced by several orders of magnitude. Another class of supramolecular assemblies involves CD polymers, where cyclodextrins are integrated in the skeleton [16-18]. It is expected that the CD polymer will bridge pendent hydrophobic groups in WSHAP solutions and thereby enhance the intermolecular associations in the solution in contrast to the CD monomers. As a result, the viscosity at low shear rate and another rheological property are enhanced.

The efficient thickening system containing CD polymers and WSHAP opens up a new dimension of functional materials development for EOR. This work is one of the few $[19,20]$ that attempts to use efficient thickening supramolecular systems formed by the host-guest interaction between WSHAPs and CD polymers for EOR. The main purpose of this work is to assess the performance of the proposed supramolecular system in heavy oil recovery. In the present work, the rheological property of the developed system was first studied to reveal its great rheological property formed through the hostguest interaction. Afterwards, sand pack tests were performed to study the flow behavior of the proposed system in porous media and the EOR performance compared with two other reference polymers. Finally, we discuss the relationship between effective viscosity and oil recovery to reveal the importance of the thickening efficiency of the polymer system in oil recovery applications.

\section{Materials and Methods}

2.1. Materials. HPAM (molecular weight, $2.0 \times 10^{7} \mathrm{~g} / \mathrm{mol}$; degree of hydrolysis, 19\%) was purchased from SNF, France. A water-soluble hydrophobically associating polymer, denoted as HAP-4, which contains a small number of pendant hydrophobic groups in backbone, was kindly provided by Guangya Polymer Chemical Co., Ltd., China (molecular weight, $6.6 \times 10^{6} \mathrm{~g} / \mathrm{mol}$; degree of hydrolysis, $22 \%$ ). Details of the preparation method and characteristic data have been reported in a previous literature [21]. A schematic of HAP-4 is shown in Figure 1.

$\beta$-CD was purchased from Wacker Biochemical Corp., China. The polymer of $\beta-C D$, denoted as CDE, was synthesized by copolymerization with epichlorohydrin. Details of its synthesis and structural characterization are reported elsewhere $[22,23]$. The polymer displays a hyperbranched architecture in which $\beta$-CD molecules are modified by poly $(2-$ hydroxypropyl)ether sequences with different lengths. Due to its hyperbranched structure, the conformation of this polymer can be quite compact, which is illustrated schematically in Figure 1. Small molecules have been removed by dialysis in this work and their molecular weight is $2 \times 10^{5} \mathrm{~g} / \mathrm{mol}$.

The crude oil sample with viscosity of $650 \mathrm{mPa} \cdot \mathrm{s}$ was used in this study.

2.2. Rheological Analysis. The aqueous polymeric solutions were prepared dissolving HAP-4 and CDE powder in water. 
TABLE 1: Physical property of the sand pack.

\begin{tabular}{|c|c|c|c|c|c|c|}
\hline \multirow{2}{*}{ property } & 1 & 2 & 3 & 4 & 5 & 6 \\
\hline & HPAM & HAP-4 & HAP-CDE & HPAM & HAP-4 & HAP-CDE \\
\hline Permeability (D) & 2.49 & 2.51 & 2.48 & 2.67 & 2.63 & 2.54 \\
\hline Length $(\mathrm{cm})$ & 25.0 & 25.0 & 25.0 & 25.0 & 25.0 & 25.0 \\
\hline Cross-sectional area $\left(\mathrm{cm}^{2}\right)$ & 4.9 & 4.9 & 4.9 & 4.9 & 4.9 & 4.9 \\
\hline Porosity (\%) & 31.6 & 32.1 & 31.2 & 32.6 & 32.5 & 32.2 \\
\hline Pore volume $\left(\mathrm{cm}^{3}\right)$ & 38.7 & 39.3 & 38.2 & 39.9 & 39.8 & 39.5 \\
\hline Shear rate $\left(\mathrm{s}^{-1}\right)$ & 7.34 & 7.34 & 7.34 & 7.34 & 7.34 & 7.34 \\
\hline Initial oil saturation (\%) & & & & 91.3 & 88.2 & 89.9 \\
\hline
\end{tabular}

The mixtures were gently stirred for $24 \mathrm{~h}$. The supramolecular polymer system with the most excellent rheological property was obtained by optimizing the component concentration, which is denoted as HAP-CDE (HAP : CDE $=0.2: 0.95 \mathrm{wt} \%$ ). It must be noted that the polymer concentration used here is much lower than that in other researches $[8,24]$. HPAM and HAP-4 solutions were directly prepared by dissolving polymer powders in water followed by gentle agitation for $24 \mathrm{~h}$.

The rheological property of the polymeric systems was measured on a HAAKE Mars III (Thermo Scientific) rheometer, equipped with a cone-and-plate geometry (diameter $60 \mathrm{~mm}$, angle $2^{\circ}$ ). For temperature sweeps, a heating rate of $1^{\circ} \mathrm{C} / \mathrm{min}$ was used at a constant shear rate $(\dot{\gamma})$ of $7.34 \mathrm{~s}^{-1}$. A solvent trap was used to minimize solvent evaporation. Flow curves were measured by increasing the shear rate by regular steps. The shear rate was varied between 0.1 and $1000 \mathrm{~s}^{-1}$. Dynamic measurements were conducted at frequencies ranging between 0.1 and $10 \mathrm{~Hz}$. All measurements were carried out in the linear response region.

2.3. Sand Pack Tests. The flow behavior in porous media and EOR performances of these three polymeric systems were studied by sand pack tests. The sand pack as granular porous media was composed of sharp-edged quartz sand grains with narrow size distribution and average size ranging from 80 to $100 \mu \mathrm{m}$. Quartz sand grains were washed by hydrochloric acid solution and distilled water three times to remove impurities.

The experimental setup included an injection system with constant-flow rate piston pumps for brine and polymer solution injecting, two containers with piston for brine and polymer solutions storage, and a sand pack with inner diameter of $2.5 \mathrm{~cm}$ and length of $50 \mathrm{~cm}$. The injection system enabled injecting either of the brine or the polymer solution into the sand pack, as shown in Figure 2. The brine route was equipped with a $0.22 \mu \mathrm{m}$ cellulose membrane. In order to remove dust and potential physical gels, all the polymer solutions were prefiltered before core flood experiment through a polycarbonate membrane with pore diameter of $3 \mu \mathrm{m}$. Both the ends of core holder were equipped with $50 \mu \mathrm{m}$ stainless steel screens to prevent sands flowing out. A back pressure regulator was used at the end of the core holder. All the polymer systems were injected at low flow rate, corresponding to a wall shear rate of $\dot{\gamma}=7.34 \mathrm{~s}^{-1}$.
The permeability was determined by injecting the brine $(2000 \mathrm{ppm} \mathrm{NaCl})$ at a low flow rate and measuring the pressure drop across the sand pack. The permeability was then determined using Darcy's Law [25].

$$
k=10 \cdot \frac{L}{A} \cdot \eta \cdot Q \cdot \frac{1}{\Delta P},
$$

where $k$ is the brine permeability $\left(\mu \mathrm{m}^{2}\right), L$ is the length of the core $(\mathrm{cm}), A$ is the cross-sectional area of the core $\left(\mathrm{cm}^{2}\right), \eta$ is the viscosity of the fluid $(\mathrm{mPa} \cdot \mathrm{s}), Q$ is the flow rate $\left(\mathrm{cm}^{3} / \mathrm{s}\right)$, and $\Delta P$ is the pressure drop across the core $(\mathrm{MPa})$.

The pore volume (PV $(\mathrm{ml})$ ) of each sand pack was calculated by the weight difference of dry and the wet sand pack completely saturated with brine divided by the brine density. The average pore radius could be calculated using the permeability and the porosity of the core by the following equation [26]:

$$
r_{p}=\left(\frac{8 \cdot k}{\varphi}\right)^{1 / 2},
$$

where $r_{p}$ is the average pore radius for brine flow $(\mu \mathrm{m})$ and $\varphi$ is the porosity (fraction).

Then, the effective shear rate in the porous media was estimated by the following equation $[27,28]$ :

$$
\dot{\gamma}=2.5 \frac{4 \nu}{r_{p}},
$$

where $\dot{\gamma}$ is the shear rate $\left(\mathrm{s}^{-1}\right), v$ is the interstitial mean velocity at flow rate $Q(v=Q /(S \cdot \varphi), S$ being the cross section of the pack), and 2.5 is a geometric factor. The sand pack parameters in the different experiments are listed in Table 1.

\section{Results and Discussion}

3.1. Rheological Property. Figure 3 presents the rheological property of HAP-CDE polymeric systems $(0.2 \mathrm{wt} \%)$ and HPAM and HAP-4, respectively. The steady shear viscosity of the HAP-CDE polymeric system is the highest within the entire shear rate range, which demonstrates the strongest thickening ability of the HAP-CDE polymeric system. Moreover, HAP-4 and HAP-CDE polymeric systems show more pronounced shear thinning behavior, which indicates that 


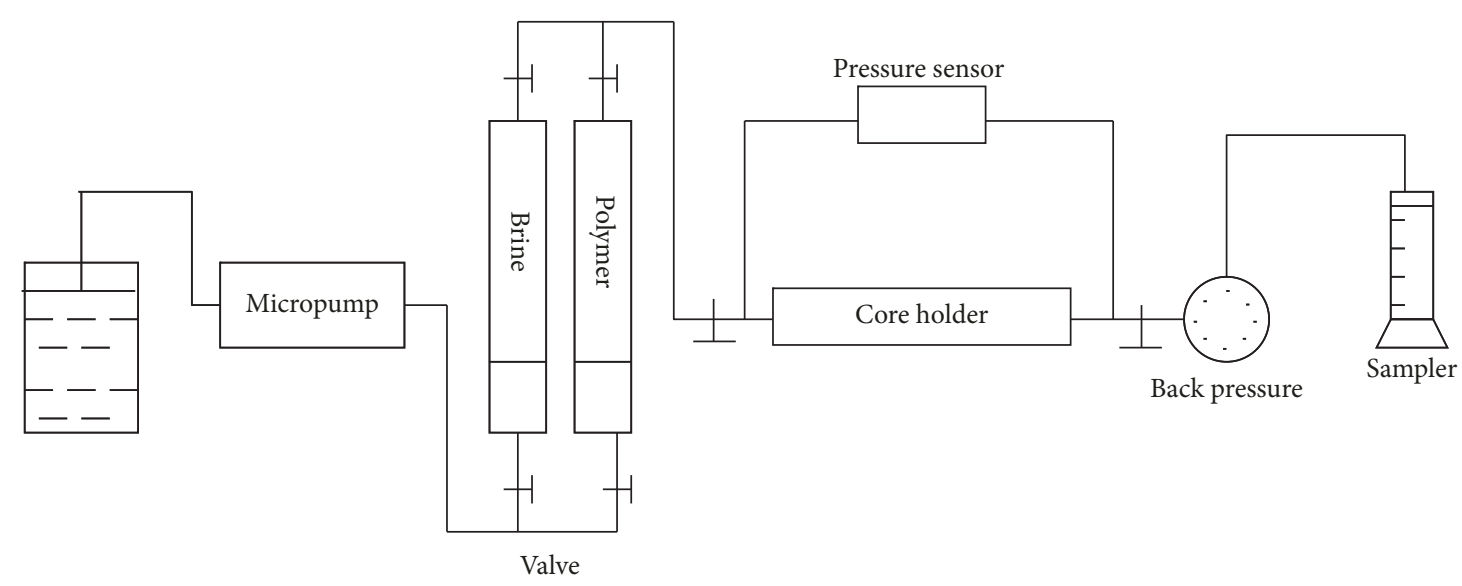

FIGURE 2: Experimental setup for sand pack test experiments.

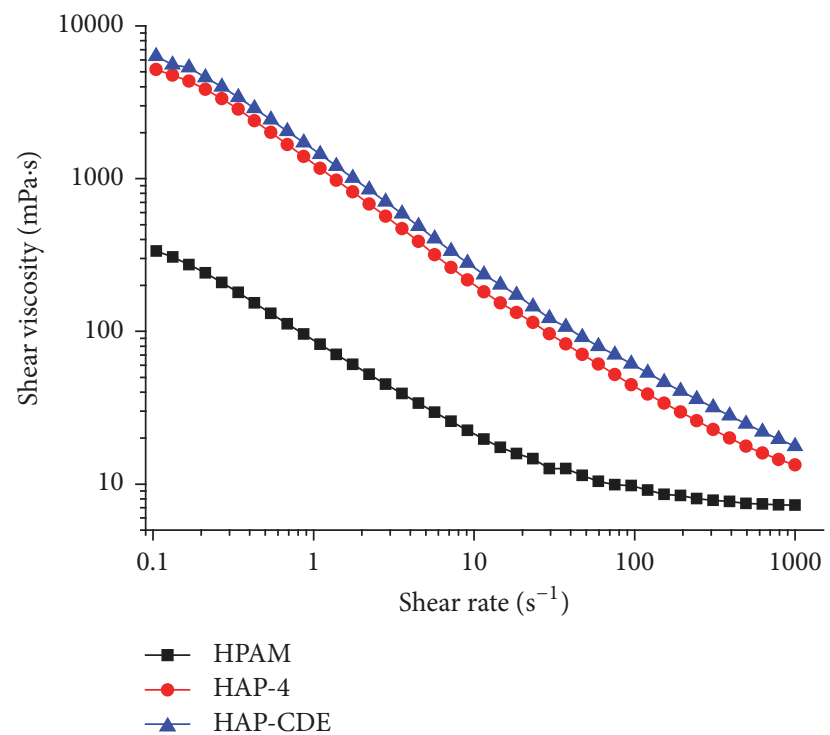

Figure 3: Shear rate dependence of the three aqueous polymeric solutions $\left(0.2 \mathrm{wt} \%, 25^{\circ} \mathrm{C}\right)$.

the intermolecular junctions can be disrupted at a rate faster than their rate of reformation. The shear thinning behavior is preferred in applications, given that low viscosity at high shear rates will save pumping energy.

The steady shear viscosity was described by power-law model (see (4)) [29], which is often used to theoretically investigate the rheological property of non-Newtonian fluids

$$
\mu=K \dot{\gamma}^{n-1},
$$

where $\mu$ is the shear viscosity ( $\mathrm{mPa} \cdot \mathrm{s}), K$ is the consistency index $\left(\mathrm{mPa} \cdot \mathrm{s}^{n}\right), \dot{\gamma}$ is the shear rate $\left(\mathrm{s}^{-1}\right)$, and $n$ is the powerlaw index.

Table 2 provides the magnitudes of slope $(n)$, intercepts $(K)$, and $R^{2}$ of the rheological data. The power-law equation was fitted to the steady shear viscosity data, which proves that three polymeric systems are typical shear thinning fluids. The highest consistency index for HAP-CDE polymeric system
TABLE 2: Rheological property of the three polymeric systems.

\begin{tabular}{lccc}
\hline Polymeric systems & \multicolumn{3}{c}{ Viscosity } \\
& $n$ & $K\left(\mathrm{mPa} \cdot \mathrm{s}^{n}\right)$ & $R^{2}$ \\
\hline HPAM & 0.404 & 91.6 & 0.996 \\
HAP-4 & 0.360 & 1321.3 & 0.993 \\
HAP-CDE & 0.366 & 1608.4 & 0.994 \\
\hline
\end{tabular}

certifies its strongest thickening efficiency. The relatively small and very approximate power-law index for the HAP4 and HAP-CDE polymeric systems suggests that both of the two systems display pronounced shear thinning behavior, which is a key characteristic for polymers in polymer flooding.

Another important property for polymer flooding is the viscoelasticity of the polymer aqueous solution, which is closely related to the microscopic displacement efficiency. In Figure 4, the storage $\left(G^{\prime}\right)$ and loss $\left(G^{\prime \prime}\right)$ moduli for $0.2 \mathrm{wt} \%$ solutions of the three polymeric systems are displayed. As it can be observed, the viscoelastic response of the HPAM solution shows good frequency dependence. At low frequency, we note that $G^{\prime \prime}>G^{\prime}$ which indicates that the viscous response dominates. At higher frequency, a crossover is detected. This feature signalizes a transition from a dominating viscous behavior to a prevailing elastic response. The curves of viscous moduli $\left(G^{\prime \prime}\right)$ and elastic moduli $\left(G^{\prime}\right)$ cross each other at a frequency of $1.5 \mathrm{~Hz}$.

It is obvious that the elastic responses in HAP-4 and HAP$\mathrm{CDE}$ polymeric systems are more pronounced and show much less frequency dependence. In both HAP-4 and APCDE polymeric systems, $G^{\prime}>G^{\prime \prime}$ in the entire study area, which indicates that the elastic response dominates. The elastic dominant behavior suggests the relatively strong network structures in HAP-4 and HAP-CDE polymeric systems. There is an obvious enhancement in Figure 4 for $G^{\prime}$ and $G^{\prime \prime}$ in HAP4 and HAP-CDE polymeric systems compared to the HPAM solution. The improved rheological prosperities of HAP-4 solution are mainly because that hydrophobic association in aqueous solution increases the hydrodynamic size of the 


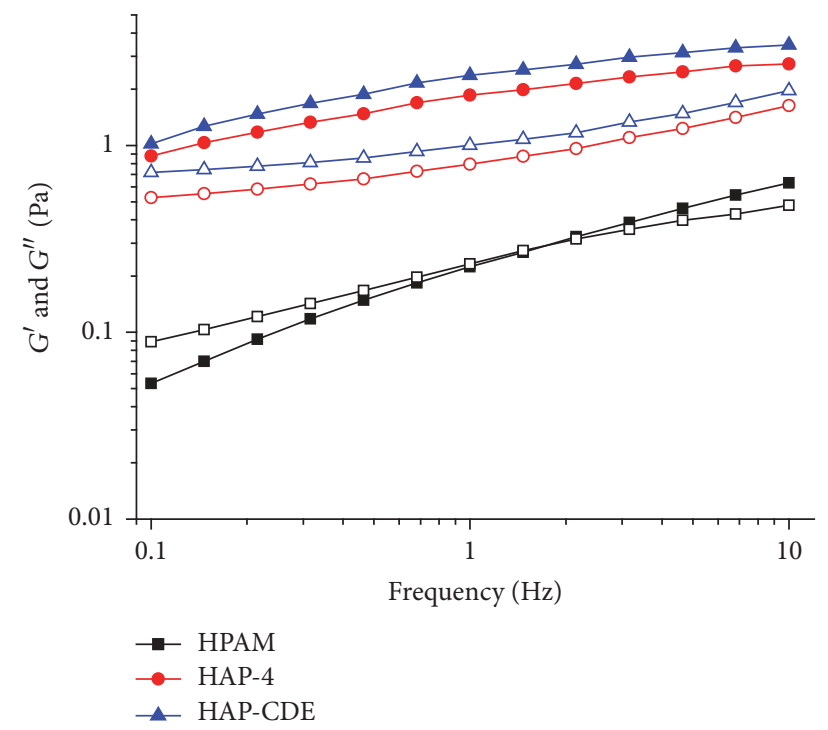

FIgURE 4: Dynamic viscoelasticity of the three polymeric systems. Closed symbols denote storage moduli and open symbols denote loss moduli $\left(0.2 \mathrm{wt} \%, 25^{\circ} \mathrm{C}\right)$.

polymer chains and consequently forms strong overall networks, whereas the further enhancement of HAP-CDE system indicates that the addition of CDE results in strong viscoelasticity enhancements of the HAP-4 solution. The strengthened network structure is attributed to the formation of intermolecular bridges $[16,30]$. In addition, when the HAP$\mathrm{CDE}$ system is subjected to rapid shear fields, the reinforced networks tend to be disrupted and display shear shinning behavior, which is evidenced by its rheological property. Although the HAP-CDE system has the highest viscosity and viscoelasticity, it can also retain a relatively low injection pressure at high flow field.

The great number of inorganic ions in underground water has a vast influence on the rheological property of polymer solution. The influences of salt $(\mathrm{NaCl})$ on viscosity of the three polymers were carried out. As shown in Figure 5, with the increase of salt concentration, the apparent viscosity of HPAM solutions rapidly decreased due to the fact that the added salt has a shielding effect on the electrostatic resistance among polymer ions. The measure of the HAP- 4 and HAP-CDE solutions displayed similar results. However, compared with HPAM solution, the HAP-4 and HAP-CDE solutions displayed higher viscosity and viscosity retention under the same $\mathrm{NaCl}$ concentration. For the HAP-4 solutions, the viscosity decrease can be partially retarded since the increase of solution salt concentration leads to the increase of hydrophobic association. And for the HAP-CDE solutions, the retarded viscosity decrease may be explained by the special network structures. The interaction of CD groups and hydrophobic groups in the solution is enhanced by the salt concentration leading to a slow decrease in viscosity.

As reservoirs have different temperatures, it is important to study the impact of temperature on the rheological property. Figure 6 shows plots of the viscosity as a function of temperature for $0.2 \mathrm{wt} \%$ solutions at a shear rate of $7.34 \mathrm{~s}^{-1}$.

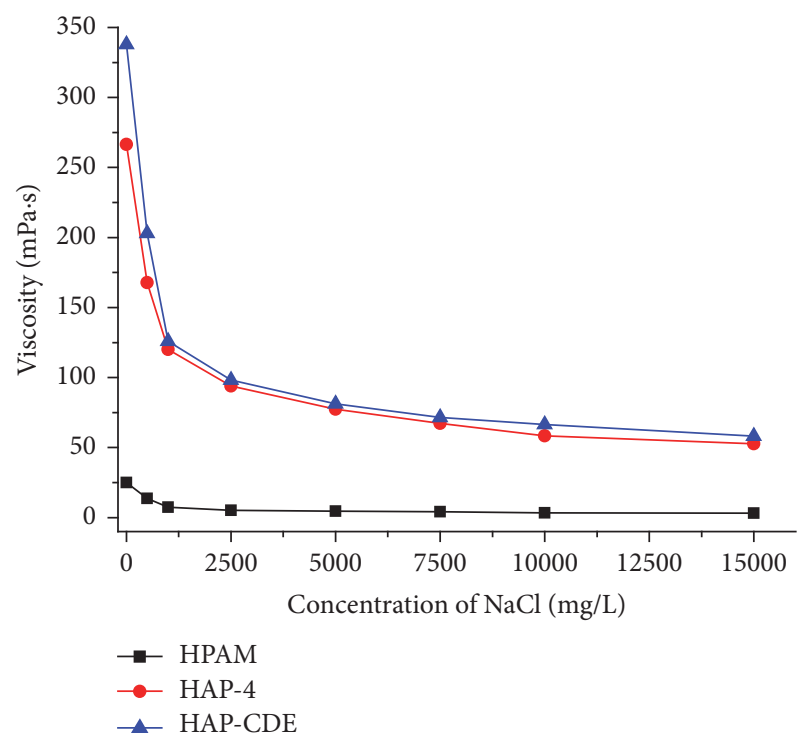

FIGURE 5: The effect of $\mathrm{NaCl}$ concentration on viscosity of polymer solutions $\left(0.2 \mathrm{wt} \%, \dot{\gamma}=7.34 \mathrm{~s}^{-1}\right)$.

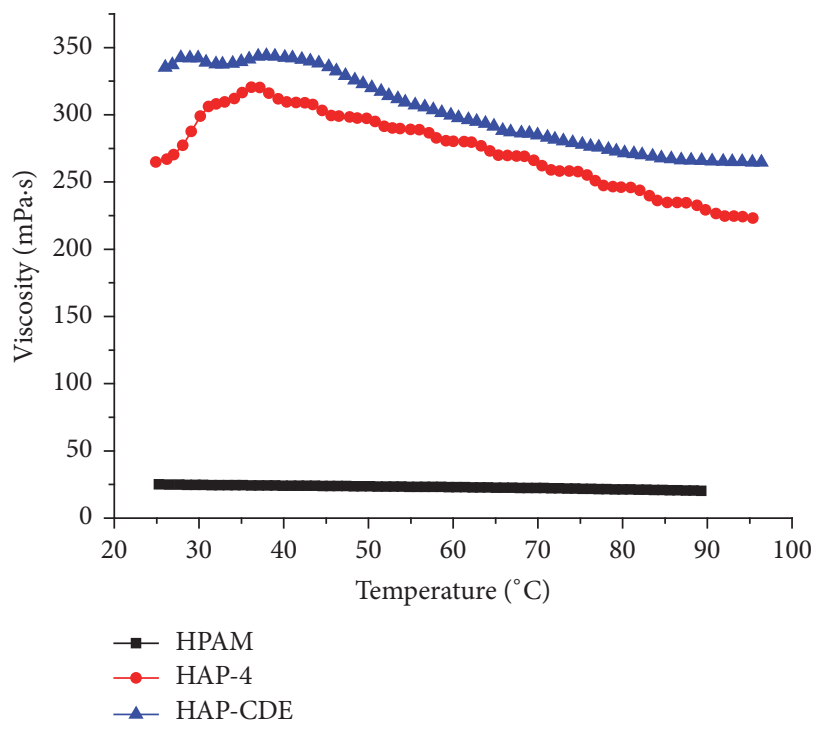

FIGURE 6: Viscosity as a function of temperature for the three polymeric systems $\left(0.2 \mathrm{wt} \%, \dot{\gamma}=7.34 \mathrm{~s}^{-1}\right)$. The viscosity decreases with temperature for the HPAM solution whereas the solutions for HAP-4 and HAP-CDE show fewer declines in viscosity.

For the most polymeric systems, increasing temperature leads to lower viscosity values. However, unusual curves are observed for HAP and HAP-CDE solutions. Both of the two solutions show an increase in viscosity over a range of temperatures ("thermothickening") followed by a drop at even higher temperatures. Thermothickening usually means the formation of more network structures. Thus thermothickening in HAP and HAP-CDE solutions should be mainly attributed to the fact that heating leads to enhanced hydrophobic association to form more or denser network structures 
in solution. A closer inspection of the curves for HAP-CDE solution reveals fewer declines in viscosity at high temperature region and the curve obviously deviates from a straight line. The reason for this unusual behavior, such as thermothickening and less viscosity decline with increasing temperature, is the enhanced thermal mobility of the HAP chains and the CDE species. As temperature rises, the polymer chains extend, in this way that the intensity of the intermolecular interaction increases [16].

Generally, the efficient thickening and strong viscoelasticity for HAP-CDE polymeric system facilitate injection fluids to improve volumetric sweep efficiency as well as microscopic displacement efficiency. The remarkable shear thinning behavior facilitates the injection of polymer into reservoirs at a relatively low pressure. The weak temperature dependence of viscosity favors the maintenance of viscosity at high temperature in reservoirs. These characteristics make the HAPCDE polymeric system a potential polymer system for enhanced heavy oil recovery.

3.2. Flow Behavior in Porous Media. Sand pack tests were conducted to study the flow behavior of these polymeric systems in porous media. The addition of polymer to the flooding fluid results in an improvement of flow resistance in the reservoir, which is partly caused by the deformation of the polymer chains as polymer solution flow through the small and tortuous pores of the porous media. Energy is converted into heat through those deformations which are caused by the shear and tensile forces during the flow process. The resistance factor (RF) is a measure of flow resistance, which provides the information about the effective viscosity of polymer slugs flowing in porous media. When we evaluate the permanent reduction in the permeability of porous media, residual resistance factor (RRF) is utilized. If we consider that the permeability reduction is mainly due to polymer adsorption, the average hydrodynamic thickness of the polymeradsorbed layer can be calculated from the RRF according to the Poiseuille equation $[28,29]$ :

$$
e=r_{p} \cdot\left(1-\mathrm{RRF}^{-1 / 4}\right),
$$

where $e$ is the average hydrodynamic thickness of polymer layer $(\mu \mathrm{m})$.

Figure 6 plots the RF and RRF as a function of PV of injection polymer slug, and the values of RF and RRF were identified at the stable stages. As a general trend, RRF increases with the PV of injection of fluids and then remains stable. The HAP-CDE polymeric system produced the highest RF value compared with other polymer systems. The highest RF value may be due to the highest shear viscosity of HAP-CDE polymeric system, as evidenced by rheological results. And on the other hand, the highest flow resistance of HAP-CDE polymeric system should also be attributed to its extensional viscosity. Generally, under the extensional flow, branched chains of polymer are stretched and become sufficiently close to each other and new entanglements start to occur, which increases the resistance against the extensional flow. Thus polymers with branched structure exhibit marked flow resistance compared with linear polymers [31]. The highest

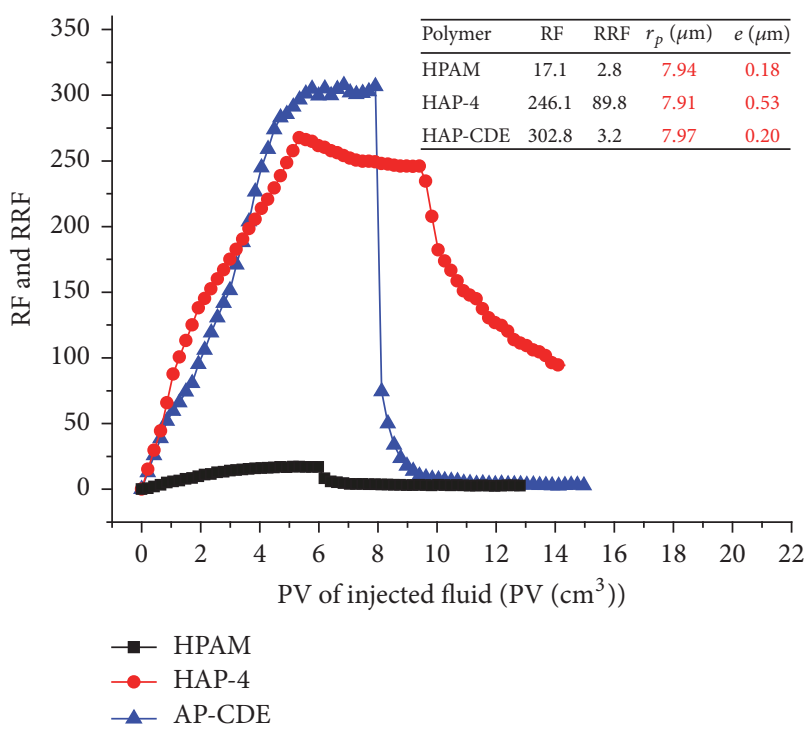

Figure 7: RF and RRF as a function of PV of the polymer slugs $\left(0.2 \mathrm{wt} \%, \dot{\gamma}=7.34 \mathrm{~s}^{-1}\right)$.

RF value compared with other polymer systems indicates the highest efficiency of the HAP-CDE polymeric system in mobility control.

An interesting result was observed on RRF. Although HAP-CDE system showed the highest RF, the highest RRF value was obtained in HAP-4 system, while the HAP-CDE system showed a relatively moderate RRF value. When injecting HAP-4 system, such elevated RRF value is likely to be attributed to the marked permeability reduction effect deduced by the formation of multiple layers composed of association of hydrophobic groups $[28,29,32]$. The moderate RRF value for HAP-CDE system indicates that the hydrophobic groups in the network have been occupied by $\mathrm{CD}$ groups of the $\mathrm{CDE}$ to form intermolecular interaction instead of polymeradsorbed layer. The obvious permeability reduction represents a serious risk for polymer injection and implies that a large amount of polymer adsorbs or is retained in the porous media, which can cause severe solution concentration loss and reservoir damage [33], while it is worthy to highlight that a moderate RRF value for HAP-CDE system can enhance its propagation in porous media to improve volumetric sweep efficiency. In consideration of the moderate permeability reduction, the highest RF value for HAP-CDE system might be mainly ascribed to the improvement of viscosity and viscoelasticity.

3.3. EOR Performance. Polymer flooding tests in sand pack were executed to evaluate the EOR performances of the three polymer systems. Water flooding was first carried out before polymer flooding to generate the residual oil saturated porous media. Figure 7 illustrates the details of the polymeric systems displacing heavy oil. And Table 3 presents an overview of the results of the heavy oil displacement tests. It can be seen that the cumulative oil recovery increased as water flooding continued. However, the increase rate in cumulative 
TABLE 3: Oil recovery from sand pack tests.

\begin{tabular}{lccccc}
\hline Entry & Initial oil saturation (\%) & $\begin{array}{c}\text { Water } \\
\text { flooding } \\
\text { recovery (\%) }\end{array}$ & Tertiary recovery (\%) & Lowest water cut in EOR (\%) & Final oil recovery (\%) \\
\hline HPAM & 91.3 & 39.5 & 10.5 & 88.9 & 50.0 \\
HAP-4 & 88.2 & 40.5 & 28.3 & 78.4 & 68.8 \\
HAP-CDE & 89.9 & 39.7 & 34.8 & 73.4 & 74.5 \\
\hline
\end{tabular}

oil recovery became very low after $2 \mathrm{PV}$ water injections due to the severe viscous fingering, resulting from the large difference in the viscosities of the heavy oil and the injection water. After about $8 \mathrm{PV}$ water injections, the cumulative oil recovery was not more than $40.5 \%$ OOIP, while the water cut of the effluent was close to $100 \%$, indicating the exhausted water flooding method. After that, a polymer slug (0.5 PV) was injected followed by an extended water flooding.

When polymer solution and extended water were injected into the sand packs, the cumulative oil recovery was increased at different degrees. Although the general trend was the same as that shown in Figure 8, the tertiary oil recovery in the case of HPAM was much lower than those of the other two cases. And only the lowest oil recovery increment could be obtained in HPAM flooding. The highest oil recovery increment was obtained by HAP-CDE polymeric system flooding.

The main reasons for the results of the polymer flooding tests are analyzed as follows. In the polymer flooding process, compared with the oil channels, the polymer slug tends to flow along the water channels with smaller flow resistance. The injection of viscous fluid (polymer solution) results in a higher injection pressure under the constant injection flow rate. And some of the trapped oils are mobilized by capillary forces. A certain start-up pressure drop is required to squeeze the trapped oil after water flooding, and the more viscous the oil is, the higher the start-up pressure drop is needed [8]. Because HPAM solution has the lowest effective viscosity, the injection of HPAM results in a relatively low injection pressure which may be lower than the previous start-up pressure drop. Therefore, HPAM flooding cannot obtain an appreciable oil recovery increment. For polymer solution with high enough effective viscosity, the increased injection pressure is above the start-up pressure drop. Water phase can penetrate in more pores and squeeze more trapped oil. The polymer solution with higher effective viscosity displayed considerably higher resistance to flow through porous media than the one with lower effective viscosity, resulting in higher sweep efficiency. The higher effective viscosity the polymer slug has, the more residual oil can be displaced out. In addition, there are increasing laboratory and field evidences that the viscoelastic characteristics of polymer solutions help to improve microscopic sweep efficiency, resulting in lower residual oil saturation $[5,6]$. The highest effective viscosity and viscoelasticity of HAP-CDE system also contribute to the oil recovery increment of HAP-CDE in polymer flooding test.

The lowest water cut and the distribution of the oil recovery at polymer and extended water flooding stages can to some extent indicate the flow pattern of polymer slug through porous media. In the polymer flooding and extended water flooding process, the lowest water cut is
$88.9 \%, 78.4 \%$, and $73.4 \%$ for HPAM, HAP-4, and HAPCDE systems, respectively. This result implies that HAP-CDE system displays a "piston-like" propagation pattern when the system flows in porous media due to its high viscosity and viscoelasticity. Compared the magnitude of the cumulative oil recovery in the polymer flooding and extended water flooding stage, $74.5 \%$ OOIP was produced by HAP-CDE system, which is $5.7 \%$ higher than HAP-4 and $24.5 \%$ higher than HPAM flooding. The higher oil recovery increment confirms that more trapped oil is squeezed and more residual oil is displaced out. By comparing the results of the polymer flooding and the flow behavior in porous media, it can be deduced that the viscosity plays a more important role in heavy oil recovery increment than permeability reduction, which is consistent with the results of previous studies [4, 34]. These results evidence the potential of this HAP-CDE polymeric system in enhanced heavy oil recovery.

\section{Conclusions}

This work evaluated the performance of the HAP-CDE polymeric system in enhanced heavy oil recovery compared to the other two polymers. The HAP-CDE polymeric system displays great rheological property. Due to its reversible interaction at the various shear rates, HAP-CDE polymeric system presents strong shear thinning behavior as implied by the power-law index $(n=0.366)$. Thermothickening and weak temperature dependence of the viscosity are also observed in HAP-CDE polymeric system, and weak viscositytemperature relation is conducive to maintain high viscosity for polymer solution under the high temperature of reservoirs. When flowing in porous media, the HAP-CDE polymeric system is able to produce higher effective viscosity than the two reference polymers and obtain a moderate RRF value, which facilitates polymer slug propagation in porous media. In heavy oil displacement tests, less than half of OOIP can be displaced by water flooding due to serious fingering. Under the condition of polymer flooding, a certain high effective viscosity phase can significantly improve oil recovery. The oil recovery was raised the greatest by the HAPCDE polymeric system flooding, in which additional $24.5 \%$ cumulative oil was produced compared to HPAM flooding. High effective viscosity and low cost systems are strongly recommended for enhanced heavy oil recovery applications.

\section{Nomenclature}

CD: Cyclodextrin

$e$ : Average hydrodynamic thickness of polymer layer, $\mu \mathrm{m}$ 

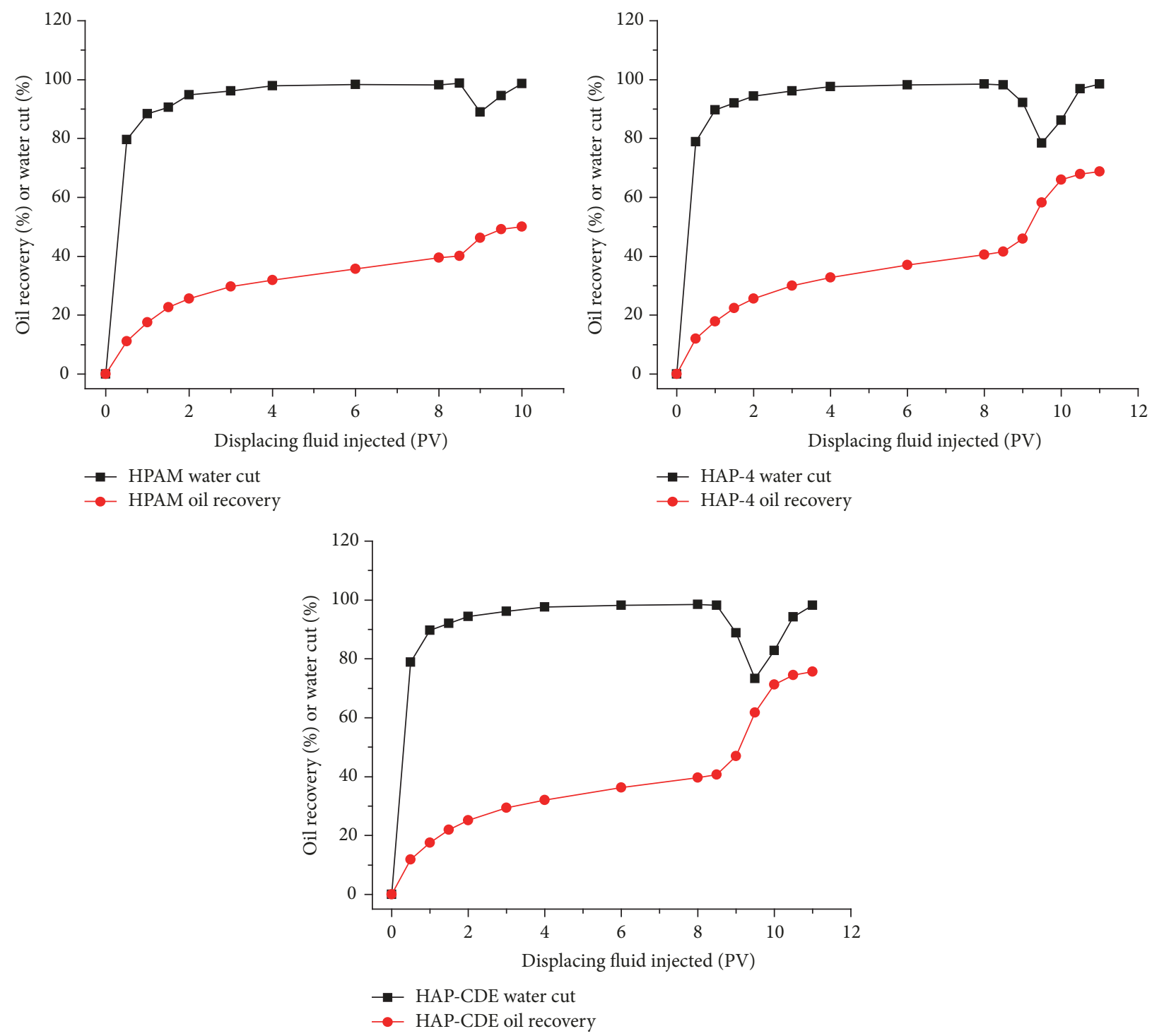

Figure 8: Oil recovery and water cut as a function of PV (0.2 wt\%).

EOR: Enhanced oil recovery

$K$ : $\quad$ Consistency index, $\mathrm{mPa} \cdot \mathrm{s}^{n}$

$k$ : $\quad$ Brine permeability, $\mu \mathrm{m}^{2}$

$L: \quad$ Length of the core, $\mathrm{cm}$

$n$ : $\quad$ Power-law index

OOIP: Original oil in place

$\triangle P: \quad$ Pressure drop across the core, $\mathrm{MPa}$

Q: $\quad$ Flow rate, $\mathrm{cm}^{3} / \mathrm{s}$

$r_{p}$ : Average pore radius for brine flow, $\mu \mathrm{m}$

RF: $\quad$ Resistance factor

RRF: Residual resistance factor

$\dot{\gamma}: \quad$ Shear rate, $\mathrm{s}^{-1}$

$\eta$ : $\quad$ Viscosity of the fluid, $\mathrm{mPa} \cdot \mathrm{s}$

$\mu$ : $\quad$ Shear viscosity, $\mathrm{mPa} \cdot \mathrm{s}$

$v$ : Interstitial mean velocity, $\mathrm{cm} / \mathrm{s}$

$\varphi$ : $\quad$ Porosity, fraction.

\section{Conflicts of Interest}

The authors declare that there are no conflicts of interest regarding the publication of this paper.

\section{Acknowledgments}

The authors are grateful to National Natural Science Foundation of China (no. 2016ZX05025-003) for financial support.

\section{References}

[1] S. Thomas, "Enhanced oil recovery-an overview," Oil \& Gas Science \& Technology, vol. 63, no. 1, pp. 1-19, 2008.

[2] D. A. Z. Wever, F. Picchioni, and A. A. Broekhuis, "Polymers for enhanced oil recovery: a paradigm for structure-property 
relationship in aqueous solution," Progress in Polymer Science, vol. 36, no. 11, pp. 1558-1628, 2011.

[3] A. Z. Abidin, T. Puspasari, and W. A. Nugroho, "Polymers for enhanced oil recovery technology," Procedia Chemistry, vol. 4, pp. 11-16, 2012.

[4] F. R. Wassmuth, W. Arnold, K. Green, and N. Cameron, "Polymer flood application to improve heavy oil recovery at East Bodo," Journal of Canadian Petroleum Technology, vol. 48, no. 2, pp. 55-61, 2009.

[5] Z. Zhang, J. Li, and J. Zhou, "Microscopic roles of 'Viscoelasticity' in HPMA polymer flooding for EOR," Transport in Porous Media, vol. 86, no. 1, pp. 199-214, 2011.

[6] T. S. Urbissinova, J. J. Trivedi, and E. Kuru, "Effect of elasticity during viscoelastic polymer flooding: a possible mechanism of increasing the sweep efficiency," Journal of Canadian Petroleum Technology, vol. 49, no. 12, pp. 49-56, 2010.

[7] J. J. Taber, F. D. Martin, and R. S. Seright, "EOR screening criteria reyisited-part 1: introduction to screening criteria and enhanced recovery field projects," SPE Reservoir Engineering, vol. 12, no. 3, pp. 189-198, 1997.

[8] J. Wang and M. Dong, "A laboratory study of polymer flooding for improving heavy oil recovery," Journal of Petroleum Science \& Engineering, vol. 67, no. 3-4, pp. 155-158, 2009.

[9] E. I. Sandvik and J. M. Maerker, "Application of Xanthan Gum for Enhanced Oil Recovery," in Extracellular Microbial Polysaccharides, vol. 45 of ACS Symposium Series, pp. 242-264, American Chemical Society, Washington, Wash, USA, 1977.

[10] K. C. Taylor and H. A. Nasr-El-Din, "Water-soluble hydrophobically associating polymers for improved oil recovery: a literature review," Journal of Petroleum Science \& Engineering, vol. 19, no. 3-4, pp. 265-280, 1998.

[11] S. Zhou, M. Han, W. Xiang, J. Zhang, W. Zhou, and W. Jiang, "Application of EOR technology by means of polymer flooding in bohai oilfields," China Offshore Oil Gas, vol. 18, no. 6, pp. 386389, 2006.

[12] B. Wei, L. Romero-Zerõn, and D. Rodrigue, "Formulation of a self-assembling polymeric network system for enhanced oil recovery applications," Advances in Polymer Technology, vol. 33, no. 3, Article ID 21413, 2014.

[13] A. Harada, Y. Takashima, and H. Yamaguchi, "Cyclodextrinbased supramolecular polymers," Chemical Society Reviews, vol. 38, no. 4, pp. 875-882, 2009.

[14] A. A. Abdala, A. E. Tonelli, and S. A. Khan, "Modulation of hydrophobic interactions in associative polymers using inclusion compounds and surfactants," Macromolecules, vol. 36, no. 20, pp. 7833-7841, 2003.

[15] S. Talwar, J. Harding, K. R. Oleson, and S. A. Khan, "Surfactantmediated modulation of hydrophobic interactions in associative polymer solutions containing cyclodextrin," Langmuir, vol. 25, no. 2, pp. 794-802, 2009.

[16] V. Burckbuchler, A.-L. Kjøniksen, C. Galant et al., "Rheological and structural characterization of the interactions between cyclodextrin compounds and hydrophobically modified alginate," Biomacromolecules, vol. 7, no. 6, pp. 1871-1878, 2006.

[17] A. Sandier, W. Brown, H. Mays, and C. Amiel, "Interaction between an adamantane end-capped poly(ethylene oxide) and a $\beta$-cyclodextrin polymer," Langmuir, vol. 16, no. 4, pp. 1634$1642,2000$.

[18] C. Galant, C. Amiel, V. Wintgens, B. Sébille, and L. Auvray, “Ternary complexes with poly( $\beta$-cyclodextrin), cationic surfactant, and polyanion in dilute aqueous solution: A viscometric and small-angle neutron scattering study," Langmuir, vol. 18, no. 25, pp. 9687-9695, 2002.
[19] C. Zou, P. Zhao, X. Hu et al., “ $\beta$-cyclodextrin-functionalized hydrophobically associating acrylamide copolymer for enhanced oil recovery," Energy \& Fuels, vol. 27, no. 5, pp. 2827-2834, 2013.

[20] X. Liu, W. Jiang, S. Gou et al., "Synthesis and evaluation of novel water-soluble copolymers based on acrylamide and modular $\beta$ cyclodextrin," Carbohydrate Polymers, vol. 96, no. 1, pp. 47-56, 2013.

[21] H. Chen, L.-J. Han, P. Xu, and P.-Y. Luo, "The thickening mechanism study of hydrophobically modified polyacrylamide," Acta Physico-Chimica Sinica, vol. 19, no. 11, pp. 1020-1024, 2003.

[22] E. Renard, A. Deratani, G. Volet, and B. Sebille, "Preparation and characterization of water soluble high molecular weight $\beta$-cyclodextrin-epichlorohydrin polymers," European Polymer Journal, vol. 33, no. 1, pp. 49-57, 1997.

[23] E. Renard, G. Barnathan, A. Deratani, and B. Sebille, "Polycondensation of cyclodextrins with epichlorohydrin. Influence of reaction conditions on the polymer structure," Macromolecular Symposia, vol. 122, pp. 229-234, 1997.

[24] D. A. Z. Wever, F. Picchioni, and A. A. Broekhuis, "Comblike polyacrylamides as flooding agent in enhanced oil recovery," Industrial \& Engineering Chemistry Research, vol. 52, no. 46, pp. 16352-16363, 2013.

[25] S. Takeuchi, S. Nakashima, and A. Tomiya, "Permeability measurements of natural and experimental volcanic materials with a simple permeameter: toward an understanding of magmatic degassing processes," Journal of Volcanology and Geothermal Research, vol. 177, no. 2, pp. 329-339, 2008.

[26] A. Zaitoun, H. Bertin, and D. Lasseux, "Two-phase flow property modifications by polymer adsorption," Oil Well, vol. 14, no. 2, pp. 285-292, 1998.

[27] G. Dupuis, D. Rousseau, R. Tabary, and B. Grassi, "Flow of hydrophobically modified water-soluble-polymer solutions in porous media: new experimental insights in the diluted regime," SPE Journal, vol. 16, no. 1, pp. 43-54, 2011.

[28] G. Dupuis, D. Rousseau, R. Tabary, and B. Grass, "Flow of hydrophobically modified water-soluble polymers in porous media: controlled resistance factors vs. flow-induced gelation in the semidilute regime," SPE Journal, vol. 17, no. 4, pp. 1196-1206, 2012.

[29] A. M. Jamieson, J. G. Southwick, and J. Blackwell, "Dynamical behavior of xanthan polysaccharide in solution," Journal of Polymer Science Polymer Physics Edition, vol. 20, no. 9, pp. 15131524, 2010.

[30] X. Guo, A. A. Abdala, B. L. May, S. F. Lincoln, S. A. Khan, and R. K. Prud'homme, "Novel associative polymer networks based on cyclodextrin inclusion compounds," Macromolecules, vol. 38, no. 7, pp. 3037-3040, 2005.

[31] T. Takahashi, J. Takimoto, and K. Koyama, "Elongational viscosity for miscible and immiscible polymer blends. II. Blends with a small amount of UHMW polymer," Journal of Applied Polymer Science, vol. 72, no. 7, pp. 961-969, 2015.

[32] E. Volpert, J. Selb, F. Candau, N. Green, J. F. Argillier, and A. Audibert, "Adsorption of hydrophobically associating polyacrylamides on clay," Langmuir, vol. 14, no. 7, pp. 1870-1879, 1998.

[33] P. Gramain, "Permeability study on adsorption phenomena of poly(vinyl acetate) in well defined porous media," Macromolecular Chemistry and Physics, vol. 176, no. 6, pp. 1875-1883, 1975.

[34] B. Wei, “ $\beta$-cyclodextrin associated polymeric systems: rheology, flow behavior in porous media and enhanced heavy oil recovery performance," Carbohydrate Polymers, vol. 134, pp. 398-405, 2015. 

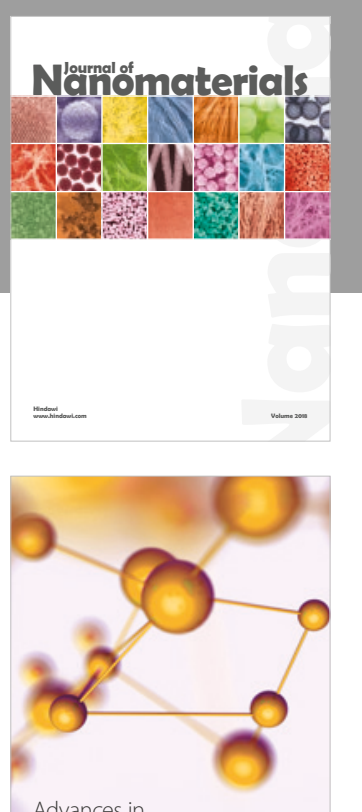

Physical Chemistry
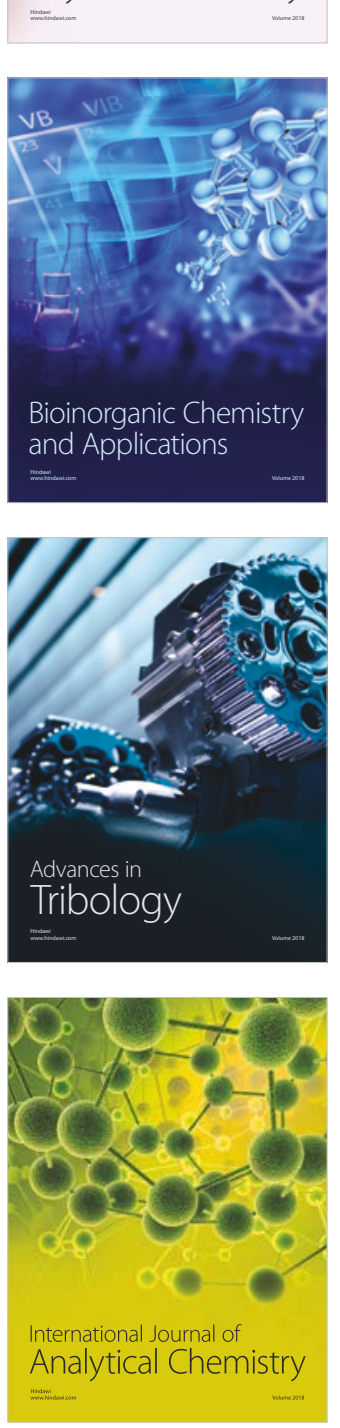

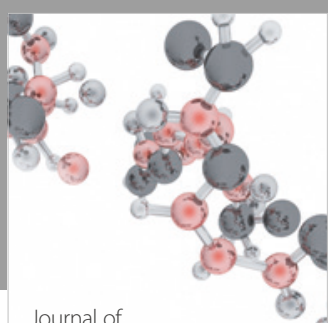

Analytical Methods

in Chemistry

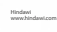

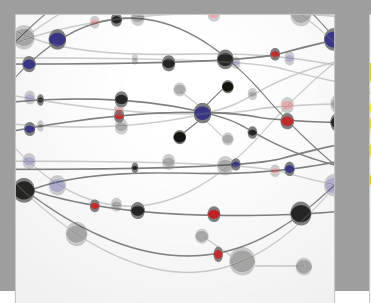

The Scientific World Journal

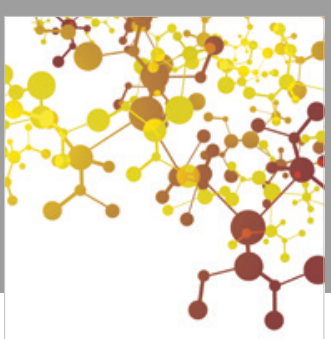

Journal of

Applied Chemistry
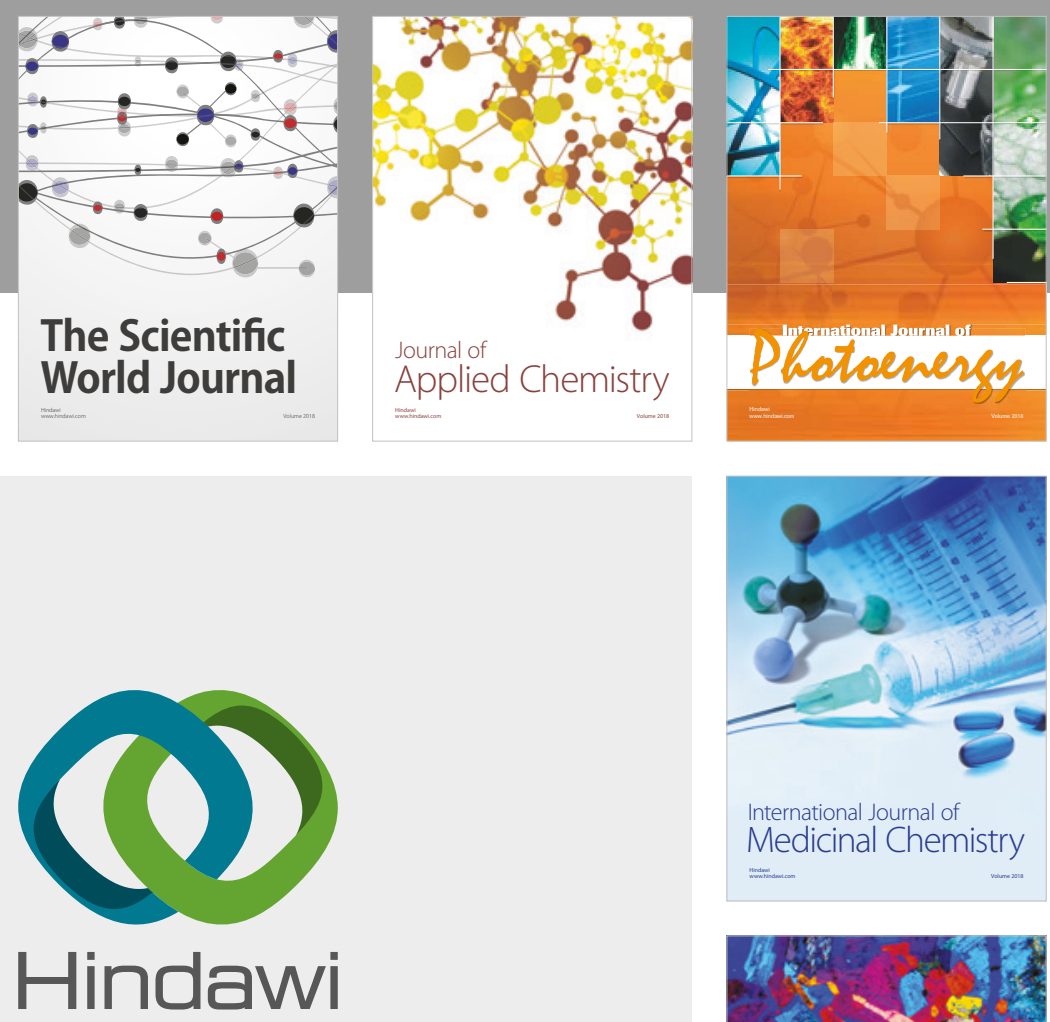

Submit your manuscripts at

www.hindawi.com
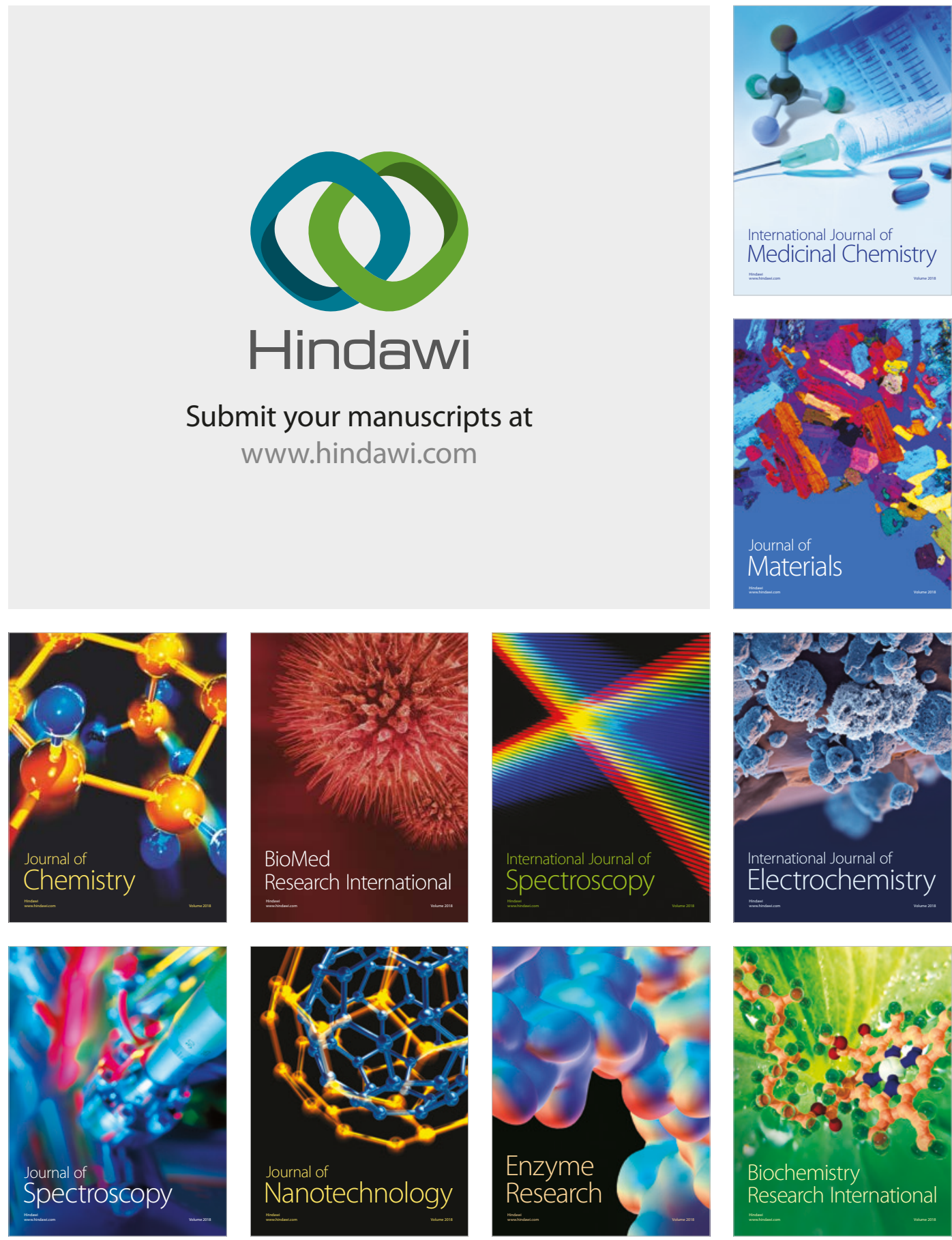
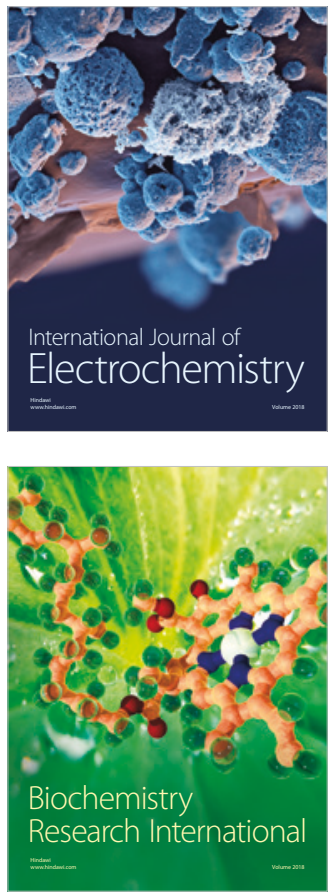